\title{
Computer Artists: A Study of Influences on Their Artistic Development and Production
}

\author{
Mia Johnson
}

I have worked in the field of art education for 26 years. I worked first as a secondary art teacher, then as an artist and art reviewer, and currently as a university art educator. I returned to the University of British Columbia to do graduate work in 1990. For the past ten years, I have been interested in how images are constructed on a two-dimensional surface. After painting imagery myself and teaching art to secondary students and adults, I studied how children make pictures. My findings were published in two books for parents, Teach Your Child To Draw and Understanding and Appreciating Your Child's Art.

During my first year of graduate studies in the Master's program, I examined the visual and neurological processes that occur during the artistic process of translating an object or scene onto a two-dimensional surface. A theoretical model was later published in Visual Arts Research 19(1), 1993. In the second year of my Master's program, I became interested in how 2D and 3D images are created with computer technology. Investigating computer graphics procedures allowed me to begin studying the theories of vision and cognitive processes that are embedded in the software and hardware itself.

Although perception and cognition have been ongoing interests, for my thesis topic I decided to focus on the kinds of terminology used in the two fields. I compared 9000 terms that are used in art education and in computer graphics to describe the appearance and construction of visual images. Dr. Ronald MacGregor was my supervisor. In this study, I analyzed the elements and principles of design as they are taught in traditional art education, and examined the extent to which they are appropriate for an aesthetic model in computer graphics. A paper describing this research will soon be published in Studies.

I am currently in the Ph.D. program for Curriculum and Instruction in art education, where I also teach computer graphics and elementary art education. I have been very fortunate in linking my interests. For example, my work at U.B.C. has allowed me to attend such professional computer graphics conferences as the Virtual Worlds Symposium and SIGGRAPH. My academic work has included doing 3D animation with Wavefront and Alias in the department of Computer Science, and making an interactive videodisk with Dr. Glorianna Davenport, M.I.T. Media Lab. As a result of my research 
into science and engineering applications of visual technology, I have become aware of the enormous degree to which knowledge in the field of art education is potentially valuable to the development of effective and powerful computer graphic images. My backgrounds in visual perception, spatial reasoning, studio work, aesthetics, and the psychological/metaphoric effects of imagery have all assisted $\mathrm{me}$ in making connections between the two fields.

The working title of my Ph.D dissertation is Computer artists: A study of influences on their artistic development and production. I decided to do a triangulated study in this area because there is so little known about adult exemplars in the field. This study is in three parts. It includes an examination of computer art images as cultural and educational artifacts; a survey of artistic and educational influences on computer artists; and interviews with computer artists. I use the term "education" to describe both formal and informal ways of learning and developing an artistic vehicle and style. I am particularly interested in finding out how gender might affect the acquisition of knowledge about computer graphics, schemata and style, or access to concrete and electronic exhibition venues.

In order to facilitate communication with computer artists, I have spent the past two years gaining hands-on computer graphics experience, a knowledge of different hardware and software, and a technical vocabulary As an examination of concrete computer art images, my dissertation investigates the schemata, content and styles that are evident in images produced by male and female computer artists. It also characterizes available sites and venues for exhibiting and disseminating computer art and theories. I am acquiring quantitative data first through content analysis of computer art for patterns of "authorship", subject matter, methods, and program idiosyncrasies, and second through survey research on the Internet with practitioners in computer graphics groups such as SIGGRAPH.

This dissertation investigates how computer artists go about acquiring their pictorial conventions, and the kinds of technical or aesthetic education they receive or acquire. It also looks at why they acquire them, in terms of the kinds of theories that inform their practice and the kinds of social interactions that influence their education, artwork, and access. The qualitative data is being acquired through semi-structured interviews with computer artists and analyzed with an ethnographic data analysis software program. The survey data is being analyzed with the support of a survey analysis program 
There is certainly a need for curriculum models in computer art education. However, there has been little research on what Howard Becker would call the "art world" of computer artists, and even less that is synthesized for educational purposes. Most studies in computer art education have been centered around questions of how children interact with a new art medium in already-familiar art education contexts. That is, the focus is predominantly on how students accept or transfer previous art experience to a computerized environment, rather than on the technologies. I believe that researchers need to examine hardware and software as it is developed and applied in industry, science and the computer art world, and do more ethnographic studies of computer artists themselves. For example, to date only two studies have been done of professional adult exemplars: Demaria's 1991 dissertation on the work of Charles Csuri and Morbey's 1992 dissertation on the work of Harold Cohen. Through critical examination of their work, artists can serve as models of theoretical and historical development in computer art.

The neglect of its history, criticisms, and theories of art leaves students and teachers unable to deal meaningfuliy with sophisticated forms of computer graphics. They are disabled in their ability to comprehend electronic art, to work with current conventions of computer art, and to take part in the development of new aesthetics. I hope that this study will assist curriculum developers in understanding the ways of knowing and learning that are shared by adult computer artists; their transition from such other fields as computer science or traditional art; their moral and ethical outlooks; and their aesthetic preferences and their artistic theories. It may reveal gender differences in computer art education and production.

i am ultimately interested in developing a discipline-based model for computer art education. Prototype models for traditional Discipline-Based Art Education recommend four areas of instruction: art history, art criticism, aesthetics, and art production. To integrate computer graphics as an emerging medium in art education and at the same time work within current models, a curriculum model would need to address these four areas. My current research indicates the need to consider; (1) the impact of traditional art history and the influence of developments in hardware and software on computer graphics history; (2) such critical values as those implicit in appropriation and simulation, as well as the effects of recognizable algorithms in commercial software; (3) the interrelationship of computer techniques with aesthetic elements of art, as well as the unique constraints and strengths of the computer medium; and (4) perceptual training in studio practice to increase powers of observation and visualizing skills for constructing computer images. 
As a graduate student at the University of British Columbia, I have been extremely fortunate to study with the following people: my advisor, Dr. Ronald MacGregor, who has a particular interest in image construction; computer scientists Dr. David Forsey and Dr. Alain Fournier of the U.B.C. Center for Integrated Computer Systems Research; Dr. Rita Irwin, a curriculum scholar and ethnographic researcher; the internationally respected art educators Dr. Anna Kindler and Dr. Graeme Chalmers; and Dr. Ken Stoddart, Department of Sociology, whose particular interest is the sociology of the arts and the conventions of art worlds. I would like to thank the Canada Council for the two-year research grant which is supporting this . study.

\section{References}

Johnson, M. (1994). Beyond the Paint Program: Computer Graphics on the High End, Journal of the Canadian Society for Education Through Art, 25, 8-12.

Johnson, M. (1993). A Cognitive Model for the Perception and Translation of a Thre日-Dimensional Object/array Onto a Two-Dimensional Surface, Visual Arts Research, 19(1), 85-99.

Johnson, M. (1994). A Cognitive Model for the Perception and Translation of a Three-dimensional Object/array Onto a Two-Dimensional Surface, Art Education Review, Annual Report of Zohyung-Kyoyouk 1994, Seoul, Korea, 10, 186-200.

Johnson, M. (1993). A Comparative Study of Visual Elements in Traditional Art Images and Computer Graphics, Unpublished master's thesis, University of British Columbia, Vancouver, British Columbia.

Johnson, M. (in press). A Comparative Study of Terms Used in Art Education and Computer Graphics to Describe the Visual Properties of Images. Studies in Art Education.

Johnson, M. (in press). Computer Painting and Perceptual Training, School Arts

Johnson, M. (1994). Drawing Against the Odds, BCATA Journal for Art Teachers, 34(2), 46-47. 
Johnson, M. (1995). The Elements and Principles of Design: Written in finger Jello? Art Education (NAEA).48(1), 57-61.

Johnson, M. (1983). Everything You Want to Know About Drawing and Painting: A Studio Guide. Vancouver B. C.: Intermedia Press

Johnson, M. (1985). The Pink Heart and Other Tamperings.

Vancouver, B.C.:Bau-Xi Gallery.

Johnson, M. (1995). Phenomenology and the Pilot Edition of the B.C. Visual Arts Curriculum. BCATA Journal for Art Teachers, 34(3), 4143.

Johnson, M. (1990).Teach Your Child to Draw, Los Angeles: RGAlowell House.

Johnson, M. (in press). Teaching Children to Value Art and Artists. Phi Delta Kappan

Johnson, M. (1993). Understanding and Encouraging Your Child's Art. Los Angeles: RGA/Lowell House. 